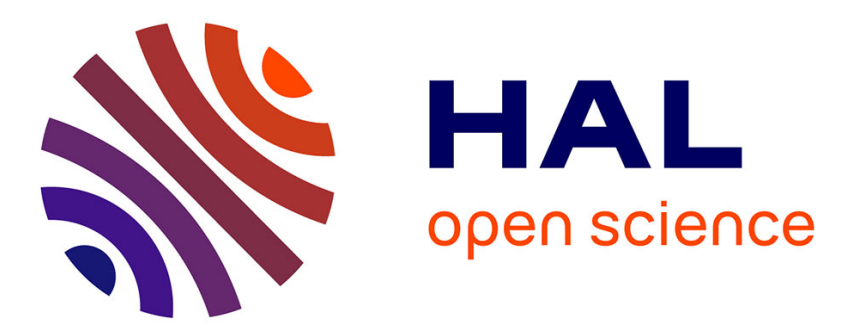

\title{
MICADO wind measurements from Observatoire de Haute-Provence for the validation of WINDII green line data
}

\author{
Gérard Thuillier, Vincent Fauliot, Michel Hersé, Ludovic Bourg, G. G. \\ Shepherd
}

\section{To cite this version:}

Gérard Thuillier, Vincent Fauliot, Michel Hersé, Ludovic Bourg, G. G. Shepherd. MICADO wind measurements from Observatoire de Haute-Provence for the validation of WINDII green line data. Journal of Geophysical Research: Atmospheres, 1996, 101 (D6), pp.10431-10440. 10.1029/95JD03522 . insu01627407

\section{HAL Id: insu-01627407 https://hal-insu.archives-ouvertes.fr/insu-01627407}

Submitted on 6 Feb 2021

HAL is a multi-disciplinary open access archive for the deposit and dissemination of scientific research documents, whether they are published or not. The documents may come from teaching and research institutions in France or abroad, or from public or private research centers.
L'archive ouverte pluridisciplinaire HAL, est destinée au dépôt et à la diffusion de documents scientifiques de niveau recherche, publiés ou non, émanant des établissements d'enseignement et de recherche français ou étrangers, des laboratoires publics ou privés. 


\title{
MICADO wind measurements from Observatoire de Haute-Provence for the validation of WINDII green line data
}

\author{
G. Thuillier, V. Fauliot, M. Hersé, and L. Bourg \\ Service d'Aéronomie du CNRS, Verrières-le-Buisson, France \\ G. G. Shepherd \\ Centre for Research in Earth and Space Science, York University, Toronto, Ontario, Canada
}

\begin{abstract}
The WINDII instrument measures the velocity of the meridional and zonal components of the wind as a function of altitude using a Michelson interferometer. Such an instrument is calibrated in the laboratory before launch. For several reasons, it is important to compare the WINDII data with other independent measurements. This should allow the confirmation of either the accuracy of the space measurements, the detection of some systematic offset, or an aging as a function of time. The MICADO interferometer has been running since the beginning of the UARS mission at Observatoire de Haute-Provence (France). The data provided by this instrument are used to perform this study. For nighttime measurements, no aging has been detected and it is found that WINDII overestimates the two components of the wind by $10 \mathrm{~m} \mathrm{~s}^{-1}$ at the latitude and longitude of the ground-based observations. This corresponds to an offset of $9 \mathrm{~m} \mathrm{~s}^{-1}$ for both fields of view. Amplitude and phase of the semidiurnal tide have also been derived from the WINDII and MICADO data as a function of season. Comparable results were obtained.
\end{abstract}

\section{Validation of WINDII Data}

\subsection{Purpose of the Validation}

The WINDII instrument uses a field-compensated Michelson interferometer to perform wind and temperature measurements as a function of altitude. Precision and accuracy of the measurements depend on the ground calibration and on its reliability from ground to space.

Calibration at ground faces the following difficulties: (1) Calibration measurements are especially difficult with a large field of view interferometer. (2) Laboratory sources, able to produce forbidden lines as those existing in the natural airglow, may have some parasitic lines.

The reliability of the ground calibration in orbit can be affected by the vibrations experienced during the launch, the space environment through high-energy particles, and outgassing and deposition of materials.

All these factors can induce a systematic error in the wind determination, small instrument deadjustments, and an aging of the instrument optics and detectors. These can reduce the precision of the temperature and wind measurements by affecting the determination of the intrinsic phase and visibility of the instrument and reduce the accuracy of the measurements through the lack of knowledge of the variation of the instrument characteristics as a function of time. Our aim is to study the reliability of the instrument zero wind phase characterization (made during fall 1990) by checking the wind values measured by WINDII and their behavior as a function of time using independent wind measurements from the ground.

This objective leads to the necessity of having a campaign of correlative measurements between WINDII in orbit and other

Copyright 1996 by the American Geophysical Union.

Paper number 95JD03522.

0148-0227/96/95JD-03522\$05.00 instruments. This paper is dedicated to the results of a correlative measurements campaign between the WINDII and the ground-based MICADO interferometer. Specific features of wind measurements from ground-based interferometers and interpretation of results have been recently reviewed in the paper by Fauliot et al. [1995] where the semidiurnal tide is studied by the use of interferometric observations from the ground at high and midlatitudes.

MICADO has been operational since the the UARS launch. This campaign of comparison has another interest since both instruments have the same design and operate with the same method [Thuillier and Shepherd, 1985]. While MICADO and WINDII are Michelson interferometers, MICADO operates on the ground and WINDII observes in orbit leading to different optical path integration. Furthermore, we must point out that WINDII was calibrated during fall 1990 and the monitoring of the spectral characteristics is made by a single source for a given line, while MICADO is checked on a daily basis using several independent sources.

\subsection{Principle of WINDII Wind Measurements}

The principle of these measurements from space have been detailed by Shepherd et al. [1993], but we need to remind the reader of the essential rationale of these measurements. From a monochromatic plane wave at wavelength $\lambda$ entering the interferometer, an interferogram is generated from which is calculated the phase $\phi$ of the wave between 0 and $2 \pi$. Let $\phi_{0}$ be the phase when the wind is null. The difference $\left(\phi-\phi_{0}\right)$ contains the wind velocity $(W)$, such as

$$
W=K_{l}\left(\phi-\phi_{0}\right)
$$

where $K_{1}$ is a constant calculated from the interferometer characteristics.

As the zero wind phase is not available in orbit, a calibration 
lamp emitting light from a line of wavelength close to $\lambda$ is used, providing a phase $\phi_{c}$. Calibration at ground consists of measuring $\left(\phi_{0}-\phi_{c}\right)$ using the same lamp as in orbit and a source able to deliver the same airglow line as in the Earth's atmosphere. The fundamental principle of the wind measurement is to assume that

$$
\left(\phi_{0}-\phi_{c}\right)_{\text {orbit }}=\left(\phi_{0}-\phi_{c}\right)_{\text {ground }}
$$

The right-hand side of the above equation is taken as a constant $\left(K_{2}\right)$ from the ground to space. As WINDII performs the measurements in two directions (fields 1 and 2), $K_{2}$ needs to be known for the two instrument fields.

Activating the calibration lamp in orbit provides $\phi_{c}$ which allows the reconstruction of the zero wind phase in orbit from

$$
K_{2}+\phi_{c}
$$

Although the above principle is simple, it contains several sources of error. When assuming a constant $K_{2}$ from the ground to space, any systematic error in the zero wind phase will be transferred to all measurements made in orbit. In addition, the impact of a change of the instrument characteristics through aging depends on the wavelength due to the chromatic property of glasses. The observed emission line and the reference source on board have close but not identical wavelength, consequently the zero wind phase reconstructed in orbit from $K_{2}$ and $\phi_{c}$ may exhibit a trend as a function of time; $\phi_{c}$ is also able to generate an error. But as the line frequency is constant, only a random error is likely to occur. This error is made negligible with respect to the other by smoothing the $\phi_{c}$ measurements over a daily basis.

Furthermore, during the instrument ground-based calibration it was not possible to use the two instrument fields of view due to particular circumstances. Field of view 2 was characterized, while for field of view 1 , results of a mathematical model of the interferometer were used in place of direct calibration measurements. This would result in transferring any systematic error in the zero wind phase from one field of view to the other.

The statistical accuracy of wind measurements has been quoted by Shepherd et al. [1993]. The statistical error is a function of altitude since it is basically linked to the number of collected photons and is also a function of time at a given altitude. Therefore for the atomic oxygen green line, at midlatitude during nighttime, a mean value of the error is $10 \mathrm{~m} \mathrm{~s}^{-1}$ around the altitude of the emission peak. Errors we have used are those given by the data processing software for each measurement.

\subsection{MICADO Instrument}

The MICADO instrument (Michelson interferometer for coordinated auroral Doppler observations) consists of a fieldcompensated Michelson interferometer [Bouchareine and Connes, 1963] which has been thermally stabilized to allow wind and temperature measurements [Thuillier and Hersé, 1991]. It is placed on the ground and is operated during nighttime. The principle of the measurement is to analyze airglow or auroral lines from their interferograms. Atmospheric lines are selected by interference filters and a movable telescope allows observations at zenith and in other directions to derive horizontal and vertical winds. In particular, it is possible to verify the homogeneity of the observed area by comparing results in two opposite directions. The accuracy of the measurements taken by MICADO depends on its wavelength reference and on the statistical error affecting the counting of the detector. Those two components usually contribute $6 \mathrm{~m} \mathrm{~s}^{-1}$ to the error in the wind determination under nighttime conditions at midlatitudes. The detailed concept, description, and calibration of this instrument are given by Thuillier and Hersé [1991].

MICADO was first operated in the auroral zone during three winter campaigns [Thuillier et al., 1990; Lilensten et al., 1992; Fauliot et al., 1993]. Afterward, it was selected as correlative experiment for the WINDII interferometer. A location at midlatitudes is appropriate to maximize the number of simultaneous measurements from WINDII in orbit and MICADO on the ground. The Observatoire de Haute-Provence $\left(44^{\circ} \mathrm{N}\right.$, $\left.6^{\circ} \mathrm{E}\right)$ has been chosen as the site from which the correlative measurements, which began in October 1991 and are continuing, are carried out.

1.3.1. Principle of MICADO measurements. When a uniform source emitting a monochromatic line of constant temperature, intensity, and velocity enters a Michelson interferometer, an interferogram is generated as a function of the optical path difference change. MICADO records an interferogram by scanning six fringes with, in general, 80 measurements per fringe. Applying Fourier analysis to an interferogram over an integer number of fringes provides intensity, temperature, and wind along the line of sight $(L)$.

As a general method, ground-based instruments use measurements at zenith as reference for the zero wind phase when one can consider that there is no direct evidence of vertical winds. At midlatitudes, vertical winds of $10-50 \mathrm{~m} \mathrm{~s}^{-1}$ have been recently observed in the thermosphere by the use of the atomic oxygen 630-nm emissions [Sipler et al., 1995]. At mesospheric heights, vertical winds of tens of centimeters per second have been measured by Meek and Manson [1989]. However, vertical profiles of the $O\left({ }^{1} S\right)$ oxygen line emission rate measured at midlatitudes by WINDII during nighttime, clearly show the absence of emission from the $\mathrm{F}$ region. Consequently, the wind phase derived from $O\left({ }^{1} S\right)$ oxygen line observations at zenith, induced only by the mesospheric vertical wind field, is negligible compared to the precision of the measurements. Under these conditions, observations at zenith provide us with the zero wind phase.

This method has been validated by special observations taken for complete nights during a few days. Variations of the instrument phase at zenith are explained by the phase variation measured using a spectral calibration lamp (krypton lamp in case of the observation of the $O\left({ }^{1} \mathrm{~S}\right)$ oxygen line emission). This explains why the phase measured at zenith is considered as reference for the zero wind phase. Furthermore, as observations in the horizontal and vertical directions are made sequentially, phases at zenith are smoothed in order to remove possible local or temporary vertical wind effect if any.

When the interferometer is operated from ground, the collected light originates from the entire emission layer, i.e., from a range of altitude in which temperature, wind, and intensity are not constant along the line of sight $(L)$. An integration along $(L)$ is made when the interferogram is recorded. This is why the derived temperature, velocity, and intensity are named apparent quantities. The meaning of the apparent quantities is dependent upon the layer shape. This problem has been carefully studied for the case of the line chosen for the correlative measurements. 

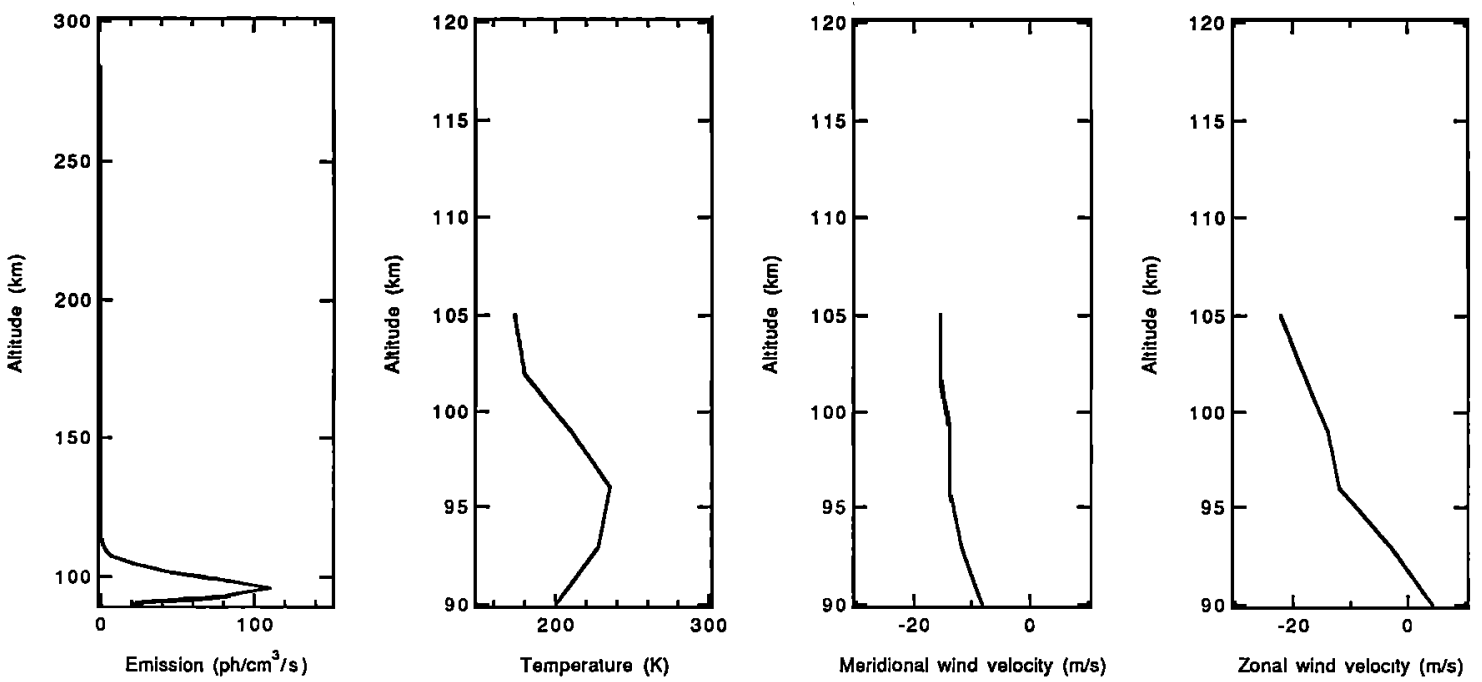

Figure 1. Vertical distribution of $\mathrm{O}^{1} \mathrm{~S}$ emission rate, temperature, and wind measured by the WINDII instrument above Observatoire de Haute-Provence (OHP) on January 30, 1992, at 0300 UT.

1.3.2. Observations by interferometry of the $O\left({ }^{1} S\right)$ oxygen line from ground at midlatitudes. A Michelson interferometer cannot operate from ground in daytime due to its high sensitivity to white light. As mesosphere winds are of importance in the UARS program, we have carried out in orbit and from ground correlative measurements using the $O\left({ }^{1} \mathrm{~S}\right)$ atomic oxygen night airglow line. This line is usually emitted in the $E$ and $F$ regions.

By calculation, it can be shown that for a single layer the apparent quantities are related to the altitude of the emission peak within a few kilometers. The correspondence is the best for the narrowest layers. For the atomic oxygen green line at midlatitudes the correspondence lies within $\pm 1 \mathrm{~km}$. But there are certain cases where the green line emission originates both from the mesosphere and from the thermosphere. We have carefully studied this situation [Faulot et al., 1995] and note that the apparent wind and temperature are dependent on the ratio of the line column brightness of each region which is, in general, not known. In particular, this study shows that the apparent temperature increases above the mesospheric value as a function of the increasing $F$ region to $E$-region brightness ratio. Fortunately, at midlatitudes the $E$-region layer zenith intensity is significantly greater than that of the $F$ region. An example is shown in Figure 1 which presents a vertical profile of the line emission rate measured at midlatitudes by the WINDII experiment [Shepherd et al., 1993]. Figure 1 clearly shows the absence of $F$-region emission which allows, in principle, to perform wind measurements in the mesosphere from ground at midlatitudes. This situation is certainly satisfied in the middle of the night. Around twilight it is possible to encounter a situation where the mesosphere is dark while the thermosphere is still lit. In that case, the contribution from the $F$ region affects the apparent quantities as observed from ground. To avoid this type of data, we define a criterion based on the value of the apparent temperature as follows:

The Doppler temperatures are around $200-250 \mathrm{~K}$ in the $E$ layer and about $1000 \mathrm{~K}$ or greater in the $F$ region. Using the $O\left({ }^{1} \mathrm{~S}\right)$ emission line, WINDII has measured the temperature at thermospheric heights during daytime and twilight at midlatitudes as well as in the auroral zone showing values significantly above the expected temperature in those conditions of obser- vations ( $800-2000 \mathrm{~K}$ depending on solar activity). This is due to the low number of thermalizing collisions of the $\mathrm{O}\left({ }^{1} \mathrm{~S}\right)$ in that altitude regime. As the two layers may contribute to the interferogram recorded on the ground, the absence of thermospheric contribution is insured by verifying that the value of the measured temperature is around $230 \mathrm{~K}$. Using the temperature criteria, most of the suspicious cases are eliminated. To prevent the keeping of certain measurements potentially having a weak $F$-region contribution, a numerical procedure of integration explained in section 2.2 has been used.

\section{Correlative Measurements Between MICADO and WINDII}

\subsection{Observations From Observatoire de Haute-Provence} (OHP) (France)

The horizontal gradients of the atmospheric parameters are expected to be smallest at midlatitudes. This condition is important when comparing data from instruments performing integrations along different lines of sight. The homogeneity of the observed area is also important since the meridional and zonal components of the wind are not obtained at the same location (typically $350 \mathrm{~km}$ with respect to the OHP station for ground-based observations). From ground the observation of the mesospheric green line emission layer leads to an optical integration path of about $20 \mathrm{~km}$. From orbit the integration path is now about $700 \mathrm{~km}$. An ideal situation would be for the line of sight of each instrument to be in the same vertical plane. In that case, the common volume of atmosphere observed by the two instruments would be small with respect to that observed by WINDII. Thus with MICADO we check the homogeneity by performing wind measurements in two opposite directions (e.g., east and west). The difference remains generally smaller than the quoted accuracy of the measurements. However, even if the MICADO observations indicate that the required level of homogeneity is achieved within the observation area, they do not allow any conclusion concerning the volume of atmosphere observed by WINDII.

The MICADO instrument installed at OHP to carry out correlative measurements with WINDII made observations as follows: (1) one hour before and one hour after each satellite 


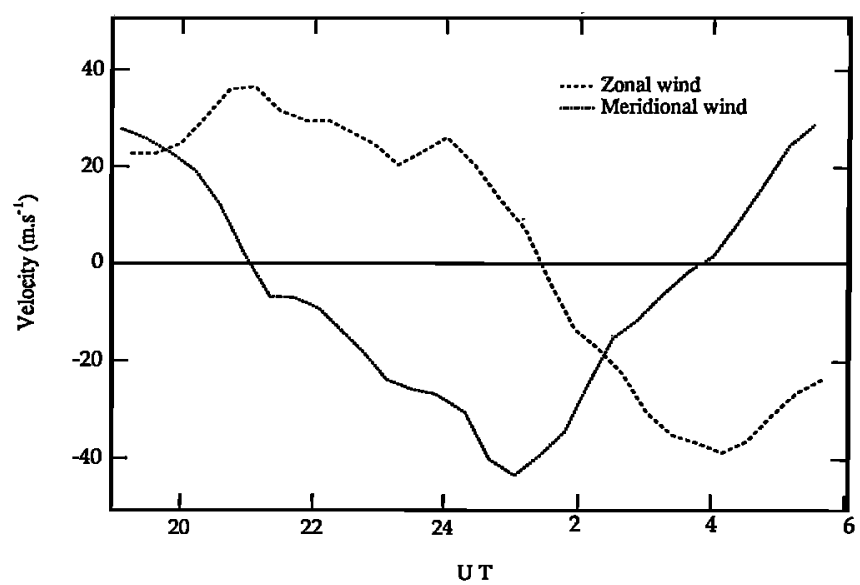

Figure 2. Local time variation of the zonal and meridional components of the wind as measured by MICADO at OHP on the night of November 7, 1990.

overpass. In certain circumstances, two to three passes were recorded. (2) A minimum of a complete night was recorded for each month in order to observe seasonal and diurnal wind variations. An example is shown in Figure 2.

Figure 3 displays the distribution and time coverage of observations gathered from October 1991 to April 1994. Their homogeneity has allowed us to study the semidiurnal tides at midlatitudes as a function of season. Results have been presented and discussed by Fauliot et al. [1995]. They agree with the major characteristics of $E$-region circulation at midlatitudes as reported by Manson et al. [1989]. Excellent agreement was found with nearby radar observations made at Monpazier [Massebeuf et al., 1981] as well as with the theoretical predictions of the Forbes and Vial [1989] model. This figure shows a lack of measurements during summer months which is mostly due to the short duration of nights and a spacecraft temporary failure in July 1992.

\subsection{Procedure for Ground to Space Comparison}

Despite the fact that the $O\left({ }^{1} \mathrm{~S}\right)$ layer in the mesosphere has a typical width of about $7 \mathrm{~km}$, an instrument placed on the ground receives photons originating from different altitudes and having different velocities and temperatures. Furthermore, when we used data measured immediately after sunset, we could not exclude the possibility that a small thermospheric contribution may exist in the ground-based data. Consequently, for all cases over OHP an integration along the MICADO line of sight $(L)$ is made, as follows, for the WINDII measurements:

$I(x)=\int_{(L)} E(z)\left(1+U V(z) \cos \left(2 \pi \frac{\Delta+x}{\lambda(z)}\right)\right) d l$

where

$\lambda$ line wavelength, including the Doppler effect induced by the wind to measure and $V$ the line visibility related to its temperature at altitude $z$;

$\Delta$ interferometer optical path difference;

$x$ optical path difference change (from 0 to $\delta$ ) to generate the interferogram;

$\delta$ total optical path change;

$U$ is the interferometer visibility.

$E(z), T(z)$, and $W(z)$ at altitude $z$ are, respectively, the emission rate, the temperature, and the velocity along the line of sight $(L)$ measured by WINDII. $T(z)$ and $W(z)$ allow calculation of $V(z)$ and $\lambda(z)$. Apparent quantities are obtained by performing an integration over altitude. It is the calculated apparent wind which is compared to the wind obtained by MICADO. All these calculations take into account the standard deviation affecting each contributing measurement.

\section{Results}

The number and distribution in time of the correlations depends upon many factors. These are spacecraft position and orientation with respect to the ground-based station, day or night condition of the pass, scheduled observations, weather at ground, instrument failures, and availability of processed data. The main restrictive factors for achieving correlations at OHP appear to be (1) the duration of the night which favors the

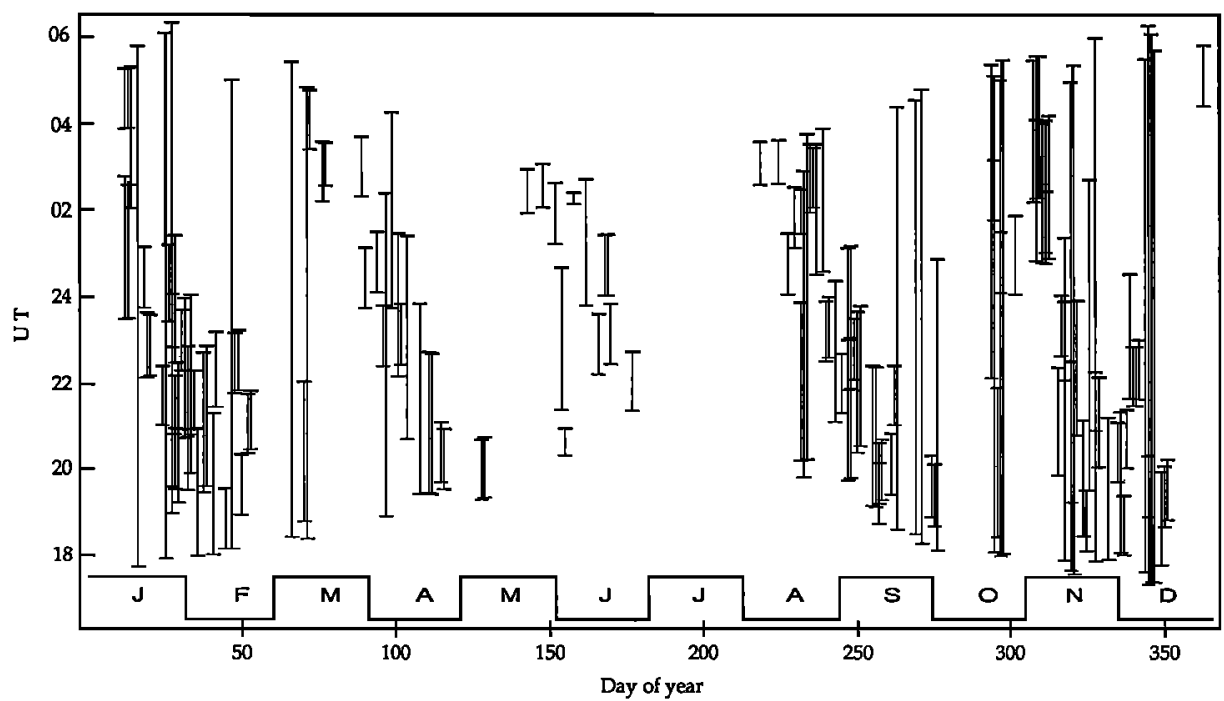

Figure 3. Distribution and time coverage of observations carried out at OHP. 


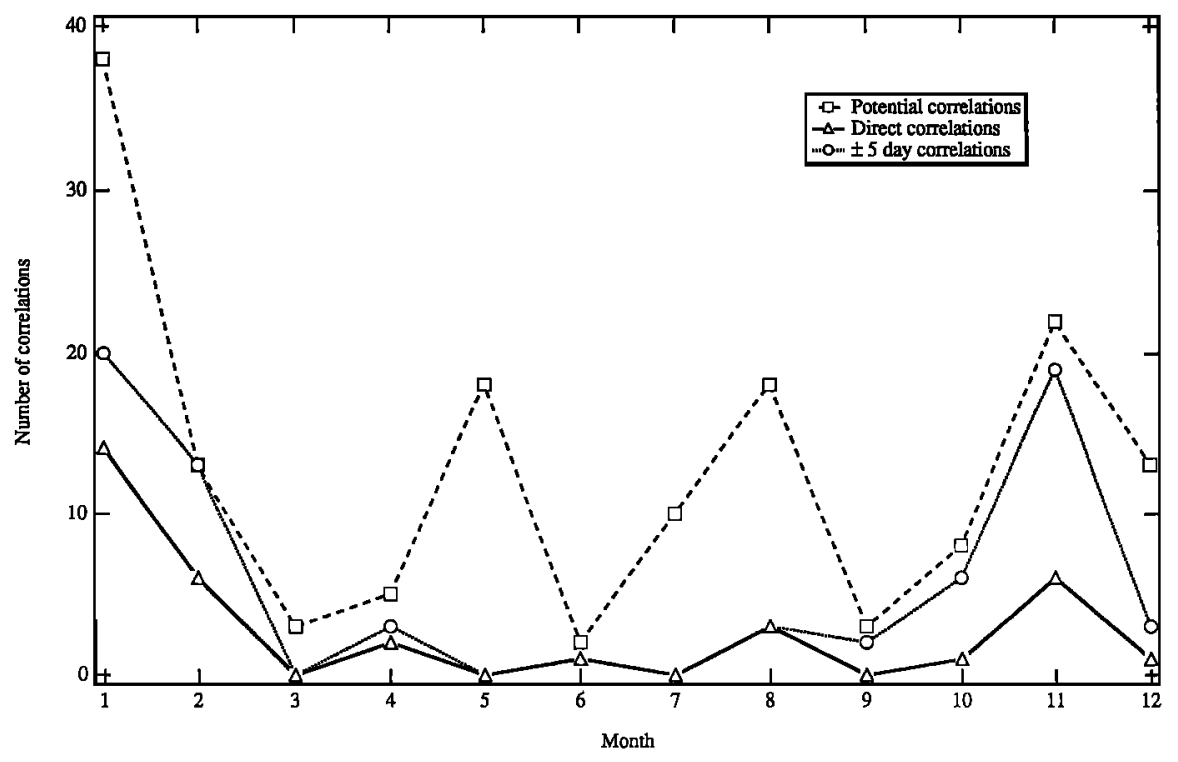

Figure 4. Number of possible and achieved correlations above OHP during the campaign of correlative measurements between WINDII and MICADO experiments.

winter months, (2) the transparency of the lower atmosphere which causes fall and spring to be less favorable than winter, (3) the spacecraft orientation which causes more correlations to occur when the spacecraft is south looking than under north-looking conditions, (4) the definition of the area for correlated measurements between the two instruments. It has been set within $\left[40^{\circ} \mathrm{N}-48^{\circ} \mathrm{N}\right]$ in latitude and $\left[10^{\circ} \mathrm{W}-20^{\circ} \mathrm{E}\right]$ in longitude, taking into account the optical integration path of both instruments.

Effects of the above experimental considerations have to be combined with the WINDII scheduled observations and data availability: (1) WINDII typically made 12 nighttime measurements per UARS month using the $\mathrm{O}^{\prime} \mathrm{S}$ line. Nevertheless, certain periods such as September 1992 and January 1993 were especially dedicated to ground correlations at OHP. (2) At the time of this paper, WINDII data had been processed with version V4.23 of the production software for the period which extends from the end of December 1991 to the end of January 1994.

Conditions of correlation between the two instruments occur for 86 days providing 153 possible correlations. Because of several factors, such as those listed above, a small number of effective correlations was found leading to consider three kinds of correlations:

Direct correlations. WINDII observations are made at the same local time and day as the MICADO measurements. During the observation periods, the meridional and zonal wind components are obtained as a function of time. These results are interpolated at the time of the WINDII measurements.

Correlations within $\pm \mathbf{5}$ days. WINDII observations are made at the same local time but within \pm 5 days with respect to the MICADO date of observation. For each month, WINDII and MICADO data were organized as a function of time in 1-hour bins.

Figure 4 shows the number of possible correlations for each month during the entire campaign. It shows that this number increases about every 3 months. This results from alternating between the yaw arounds of the spacecraft and the nighttime passes in the correlation area. The number of possible corre- lations is significantly greater in January than for the other months because 3 years of WINDII data were gathered for that month while only 2 years were available in the data set for the others. Achieved direct and \pm 5 -day correlations are also displayed in this figure. Since the occurrence of correlative measurements depends on coordination of both the WINDII and the MICADO operations, most of the correlations are obtained during the winter months from October to February. Figure 4 shows that the number of possible and achieved correlations have the same variation with season.

Numerous uncorrelated WINDII and MICADO O('S) observations are available at this time. It is also interesting for validation to compare scientific results derived from both data sets. For both components of the wind, we will focus the comparison on the seasonal variation of the semidiurnal tidal amplitude and phase. The direct and within 5-day sets of data are not totally independent since measurements of the former are included in the latter. Nevertheless, the second data set contains about twice as many points. Consequently, any significant statistical difference between the direct correlation data set and the remaining points of the \pm 5 -day correlation data set would show up in the final results. Alternatively, the absence of such a difference should further increase the level of confidence of results derived from the analysis of the two data sets. The same remark applies to the third set of data based on a monthly average more especially as the number of measurements involved is now about 4 times greater than that in the direct case.

\subsection{Trend}

As stated in section 1.2, the main consequence of aging is the existence of a long-term drift of the zero wind phase in orbit. Consequently, a drift with time could occur between WINDII and MICADO wind values. Direct correlations have been used to investigate this aspect since they provide the best conditions for comparing the measurements from each instrument. Differences between the horizontal wind components measured by WINDII and MICADO have been analyzed as a function of time to search for a linear trend. The corresponding meridi- 
a)

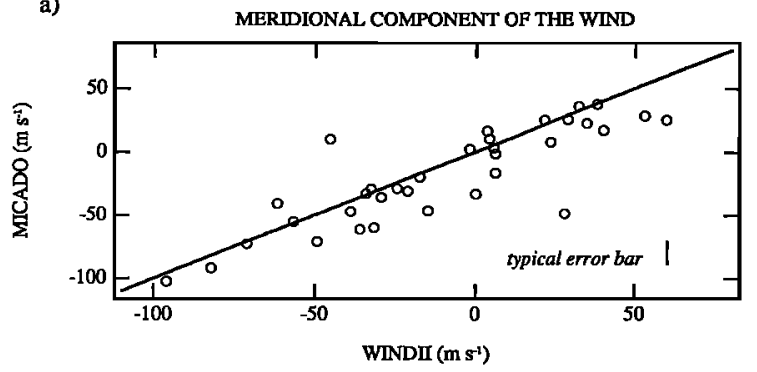

b)

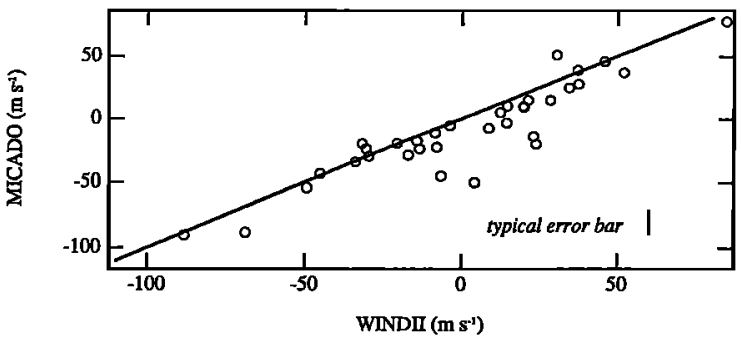

Figure 5. Relationship between the wind measured by WINDII and MICADO above OHP for the direct correlation cases: (a) meridional component, (b) zonal component.

onal and zonal slopes are $8 \times 10^{-3}$ and $3 \times 10^{-3} \mathrm{~m} \mathrm{~s}^{-1}$ per day, respectively. Taking into account the accuracy of the WINDII and MICADO measurements, the standard deviation of both slopes are $10^{-2} \mathrm{~m} \mathrm{~s}^{-1}$ per day. At the end of the correlation period the expected drift could reach $\pm 13 \mathrm{~m} \mathrm{~s}^{-1}$. This cannot be detected from the MICADO and WINDII individual measurements considering their respective accuracies.

\subsection{Direct Correlations}

For the period of WINDII data availability, 34 direct correlations were made over 21 days. Three of them were discarded for the following reason: Considering in detail the corresponding WINDII vertical profiles of those particular cases, it was found that either the intensity or the wind or the temperature were not correct with respect to the other profiles obtained in similar conditions. The failure in the retrieval process has several origins, including the homogeneity of the observed area, scattered light, and incorrectly removed star contribution. For these cases, there are differences of the order of 40 to $60 \mathrm{~m} \mathrm{~s}^{-1}$ between WINDII and MICADO. It must be noted that such profiles do not invalidate the overall data set as illustrated by $M c L a n d r e s s$ et al. [1994] results using zonal averaged data.

Finally, 31 direct correlations remain and represent $22 \%$ of the possible total. Figures $5 \mathrm{a}$ and $5 \mathrm{~b}$ show the WINDII mea- a)

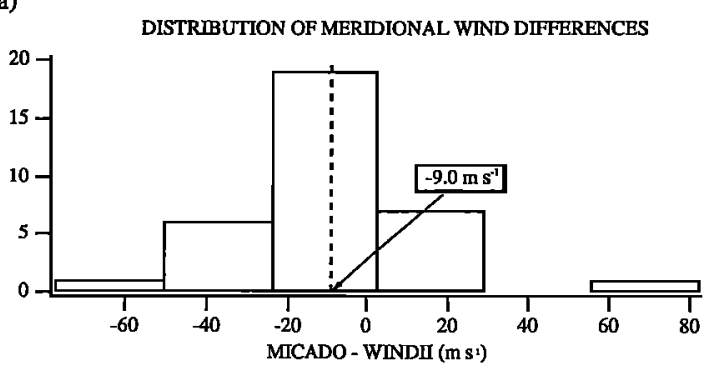

b)

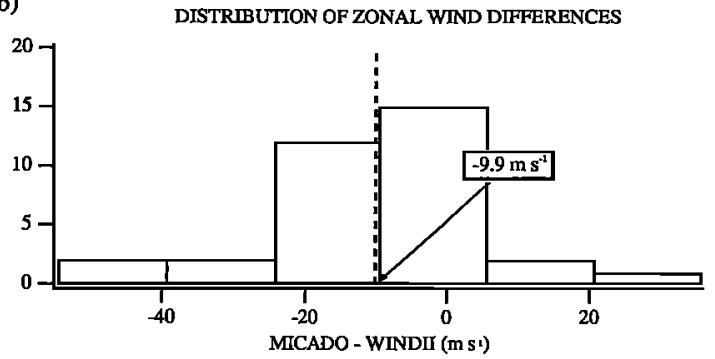

Figure 6. Distribution of the wind difference between MICADO and WINDII measurements for the direct correlation cases: (a) meridional component, (b) zonal component.

surements displayed versus MICADO for both components. The points are found near the bisector. The velocity range of these correlations extends from -100 to $80 \mathrm{~m} \mathrm{~s}^{-1}$ allowing the distribution of MICADO-WINDII differences to be determined. These are shown in Figures $6 \mathrm{a}$ and $6 \mathrm{~b}$. For both components the mean differences are close at around $-10 \mathrm{~m} \mathrm{~s}^{-1}$. This value and the corresponding standard deviation are given in Table 1.

\subsection{Correlations Within \pm 5 Days}

Within \pm 5 days between the WINDII and the MICADO measurements the number of effective correlations increases to 70. While the percentage of achieved correlations for the direct case was only $22 \%$, it increases to $46 \%$ of the possible total for the \pm 5 -day correlations.

MICADO versus WINDII winds are displayed in Figures $7 \mathrm{a}$ and $7 \mathrm{~b}$ for the meridional and zonal components, respectively. The corresponding distributions of differences are shown in Figures $8 \mathrm{a}$ and $8 \mathrm{~b}$. For \pm 5 -day correlations as well as for direct ones, there is a linear dependence between WINDII and MICADO measurements. Yet, the slope between the two data sets is different from unity for \pm 5 -day correlations. This may result from the fact that for \pm 5 days, one WINDII observation may correspond to several MICADO measurements, so that the MICADO value associated with the WINDII one is an average. This can partly explain the scatter on Figure 7 which

Table 1. Mean Values and Standard Deviations of MICADO-WINDII Differences for Two Components of the Wind Listed for Direct Correlations, Correlations Within \pm 5 days, and Monthly Means Averaged Over a Year

\begin{tabular}{|c|c|c|c|c|c|c|}
\hline \multirow[b]{2}{*}{ Component } & \multicolumn{2}{|c|}{ Direct } & \multicolumn{2}{|c|}{ \pm 5 days } & \multicolumn{2}{|c|}{ Monthly } \\
\hline & Meridional & Zonal & Meridional & Zonal & Meridional & Zonal \\
\hline $\begin{array}{l}\text { Mean, } \mathrm{m} \mathrm{s}^{-1} \\
\sigma, \mathrm{m} \mathrm{s}^{-1}\end{array}$ & $\begin{array}{r}-9.0 \\
21.1\end{array}$ & $\begin{array}{r}-9.9 \\
15.1\end{array}$ & $\begin{array}{r}-11.8 \\
31.8\end{array}$ & $\begin{array}{r}-8.9 \\
25.9\end{array}$ & $\begin{array}{r}-12.4 \\
23.8\end{array}$ & $\begin{array}{r}-10.1 \\
21.7\end{array}$ \\
\hline
\end{tabular}


contributes to the apparent bias. Further investigations show that the correlation coefficient increases while the number of observations decreases when considering correlations within \pm 5 days ( 0.62$), \pm 2$ days ( 0.71$)$, and \pm 1 day (0.74), respectively. This clearly indicates that the time range plays a significant role likely due to the day-to-day variability of the wind field (e.g., planetary waves). In addition, since direct cases (section 3.3) and the seasonal variation of the semidiurnal amplitude (section 3.6) do not exhibit any bias, it is unlikely that WINDII and MICADO could be a biased system. It is acknowledged that the detailed origin of the apparent bias is not fully explained at this time and needs further study. For both components the mean differences are close to the results obtained in the case of the direct correlations (Table 1).

\subsection{Comparison Between WINDII and MICADO Local Time Variation of the Wind}

For each month of the year, MICADO data and WINDII observations nearby OHP were organized as a function of local time and averaged over 1-hour boxes. For each local time, each MICADO point contains measurements gathered during most of days of the month. For WINDII, only one or two observations are used because UARS goes through 1 hour local time in 3 days, so that local time is aliased against the days of the month. In addition, we use WINDII data, extending over a 3-year period, which are taken under different viewing conditions and finally gathered into boxes at a given local time. As is discussed in section 3.5, an offset zero wind phase reference leads north- and south-viewing conditions to introduce different offsets when combining the two fields of view measurements. Consequently, for WINDII the averaging is less efficient than for MICADO and besides the atmosphere variability, the sampling may induce some bias. Figure 9 displays the WINDII and MICADO winds as a function of local time for January. The WINDII curve can be described in terms of a mean local time variation and a dispersion around this mean. From the previous discussion, it appears that the com-
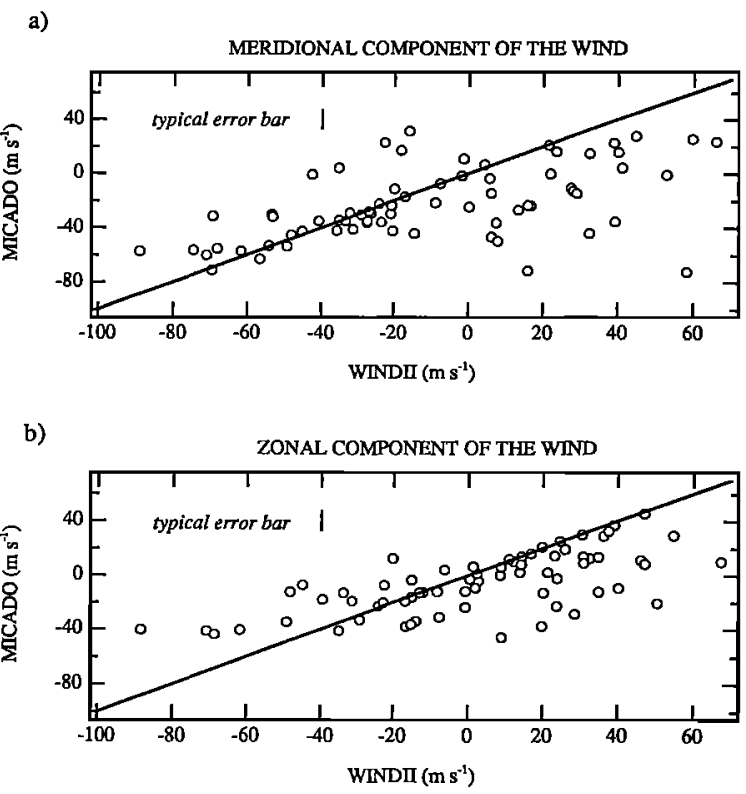

Figure 7. Relationship between the wind measured by WINDII and MICADO above OHP for correlations within \pm 5 days: (a) meridional component, (b) zonal component.
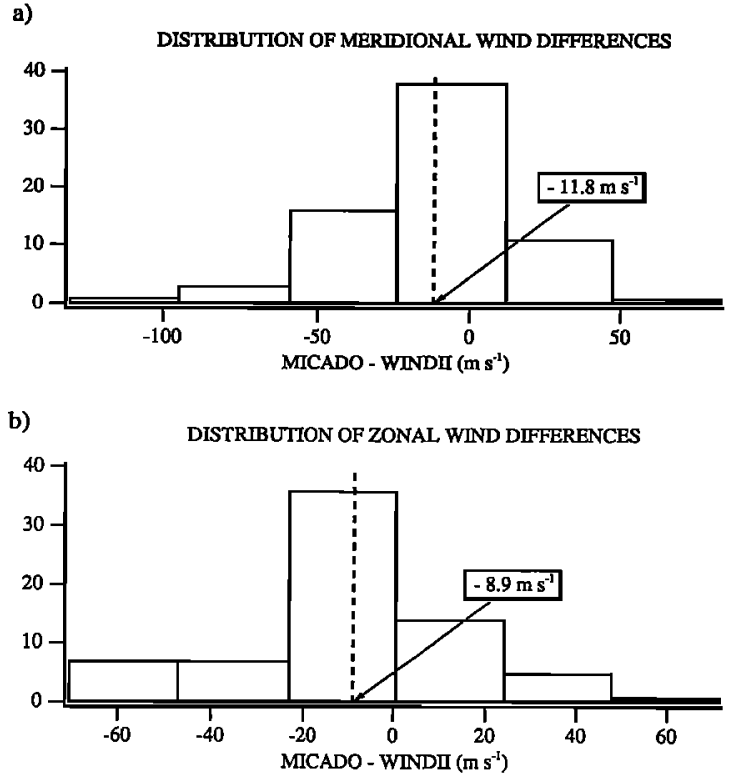

Figure 8. Distribution of the wind difference between MICADO and WINDII measurements for correlations within \pm 5 days: (a) meridional component, (b) zonal component.

bined effects of the sampling and of the atmosphere variability are not randomly distributed. Consequently, they are likely the sources of the dispersion but are also able to generate a random bias in the monthly mean difference. Indeed, Table 2 shows that the mean differences are variable with the months due to different observation conditions (viewing and number of measurements). To improve the averaging effect, all months have been considered and the corresponding differences have
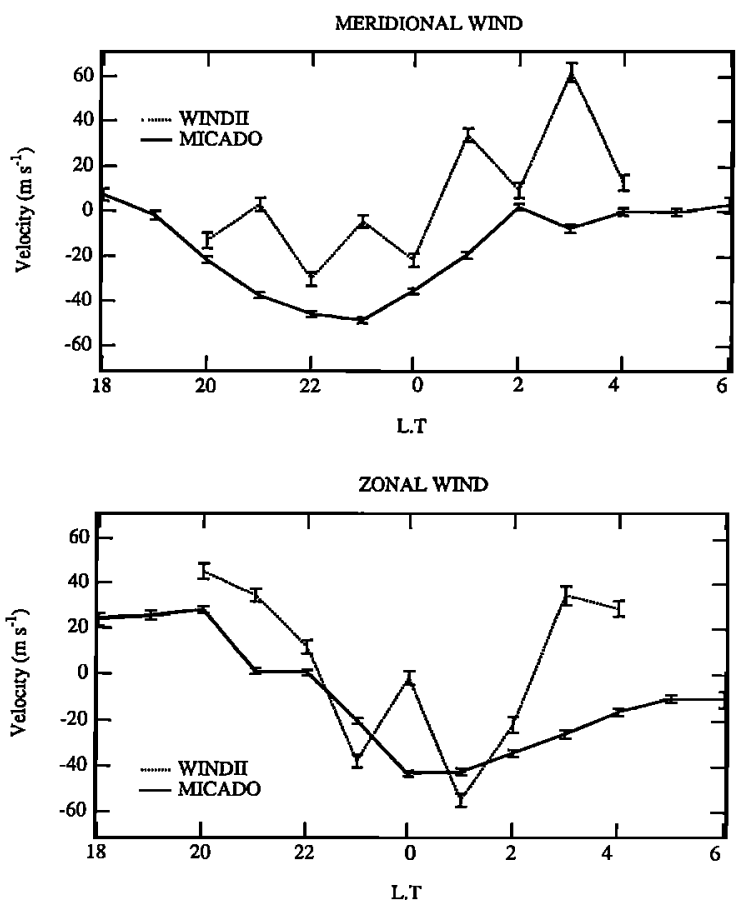

Figure 9. Comparison between the local time average of OHP observations and WINDII measurements for the month of January and the two components of the horizontal wind. 
Table 2. Number of Observations and Covered Local Time for Each Month As Well As the Mean Difference and the Associated Standard Deviation for Both Components

\begin{tabular}{lcccccc}
\hline Month & $\begin{array}{c}\text { Number of } \\
\text { Observation }\end{array}$ & $\begin{array}{c}\text { Number } \\
\text { of LT }\end{array}$ & $\begin{array}{c}\text { Meridional } \\
\text { Mean, } \\
\mathrm{m} \mathrm{s}^{-1}\end{array}$ & $\begin{array}{c}\text { Meridional } \sigma, \\
\mathrm{m} \mathrm{s}^{-1}\end{array}$ & $\begin{array}{c}\text { Zonal Mean, } \\
\mathrm{m} \mathrm{s}^{-1}\end{array}$ & $\begin{array}{c}\text { Zonal } \sigma \text {, } \\
\mathrm{m} \mathrm{s}^{-1}\end{array}$ \\
\hline January & 38 & 9 & -29.5 & 22.8 & -21.2 & 26.2 \\
February & 13 & 4 & 15.5 & 34.7 & -10.8 & 25.7 \\
March & 3 & 1 & -1.1 & 26.1 & -12.6 & 27.3 \\
April & 5 & 4 & -10.7 & 27.6 & -18.1 & 16.1 \\
August & 18 & 5 & -26.4 & 14.7 & -16.9 & 29.1 \\
September & 3 & 1 & -17.0 & 21.5 & -5.0 & 23.2 \\
October & 8 & 5 & -18.4 & 11.4 & -1.8 & 9.2 \\
November & 22 & 8 & -12.2 & 24.3 & -8.1 & 17.9 \\
December & 13 & 7 & -11.7 & 23.8 & -22.0 & 23.7 \\
\hline
\end{tabular}

been averaged over a year. We have verified that the resulting mean difference of about $10 \mathrm{~m} \mathrm{~s}^{-1}$ between WINDII and MICADO is statistically significant. For that purpose the Student's test has been applied to the WINDII and MICADO data set. This shows that the difference of means remains significant (above 90\%) above 8 and $6 \mathrm{~m} \mathrm{~s}^{-1}$ for the meridional and zonal component, respectively. These conditions are satisfied with our results. For both components the annual mean difference and its standard deviation are given in Table 1.

\subsection{MICADO-WINDII Wind Difference Related to Each Instrument Field of View}

In this section we investigate the impact of a bias of the zero wind phase for each field of view on the reconstructed meridional and zonal components of the wind taking into account the geometry of observations made in orbit. Let $\Delta_{1}$ and $\Delta_{2}$, be the offset applied to each WINDII field of view, respectively. Let $\Delta_{M}$ and $\Delta_{Z}$ be the differences between WINDII and MICADO for the meridional and zonal wind component, respectively. Each direct correlation provides $\Delta_{M}, \Delta_{Z}$, and the line-of-sight angle of the WINDII fields of views 1 and 2 which contribute to the recombination. Then, it is possible to derive $\Delta_{1}$ and $\Delta_{2}$, the corresponding offset for each WINDII field of view by inverting the equations of projection. Statistical analysis of direct correlations following that procedure leads to a mean offset of $9 \mathrm{~m} \mathrm{~s}^{-1}$ for both fields of view (Table 3). This is consistent with the same type of systematic error made during the instrument characterization. Furthermore, since the zero wind phase was measured only for one field at ground and the zero wind phase of the other field was obtained by symmetry using a mathematical model of the interferometer, it is natural that in the case of a systematic error the error propagates simultaneously in both fields in the same manner.

Let us assume that a given offset exists for each field of view. We have pointed out above that this systematic wind shift would affect differently the calculated meridional and zonal winds according to the viewing direction. Moreover, as the

Table 3. Mean Values and Standard Deviations of MICADO-WINDII Differences for Two Fields of View of WINDII As Derived From Direct Correlations

\begin{tabular}{lcc}
\hline & FOV 1 & FOV 2 \\
\hline${\text { Mean, } \mathrm{m} \mathrm{s}^{-1}}_{\sigma, \mathrm{m} \mathrm{s}^{-1}}$ & -9.2 & -8.9 \\
& 23.9 & 20.8 \\
\hline
\end{tabular}

FOV, field of view.
WINDII line-of-sight angle changes along the orbit, the magnitude of the error of the wind components appears to be a function of latitude and longitude. This is illustrated in Figure 10 for which the offset on fields of view 1 and 2 was set to $9 \mathrm{~m}$ $\mathrm{s}^{-1}$. Then, we derive the resulting offset for the meridional and zonal wind components along the orbit under south- and north-looking conditions, respectively. South- or north-viewing conditions give similar results. The northward component of the observed wind remains overestimated along the orbit track with a magnitude twice as large at extreme latitudes than at about $-20^{\circ}$ of latitude for south-viewing and $+20^{\circ}$ for northviewing conditions. For the eastward component the wind velocity is at one time overestimated and at another time underestimated with the same magnitude depending upon the upleg or downleg orbit track. In all cases the induced wind offsets are within $\pm 12 \mathrm{~m} \mathrm{~s}^{-1}$.

a)

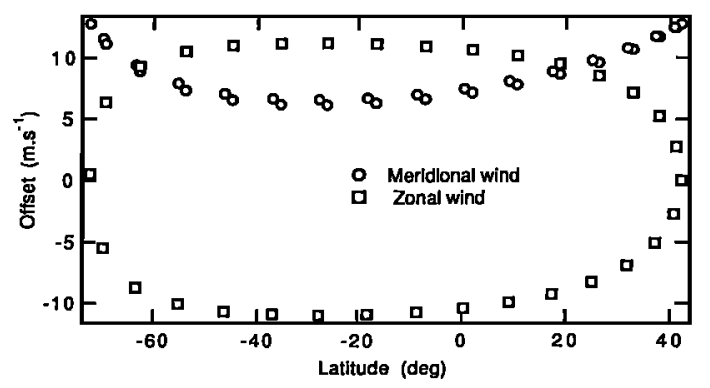

b)

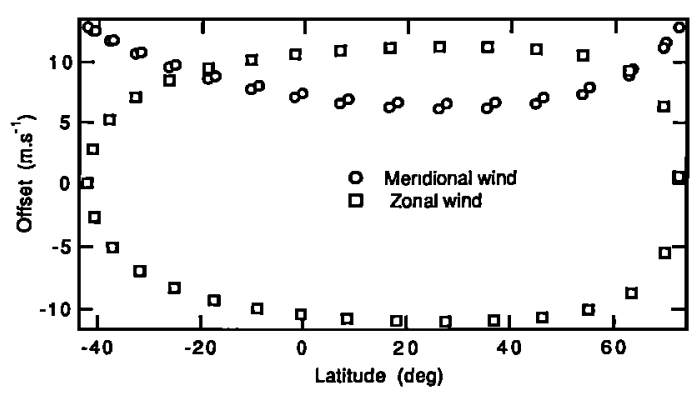

Figure 10. Meridional and zonal wind offsets along the orbit track as induced by a constant offset of $9 \mathrm{~m} \mathrm{~s}^{-1}$ on both fields of view: (a) under south-viewing conditions, (b) under northviewing conditions. 

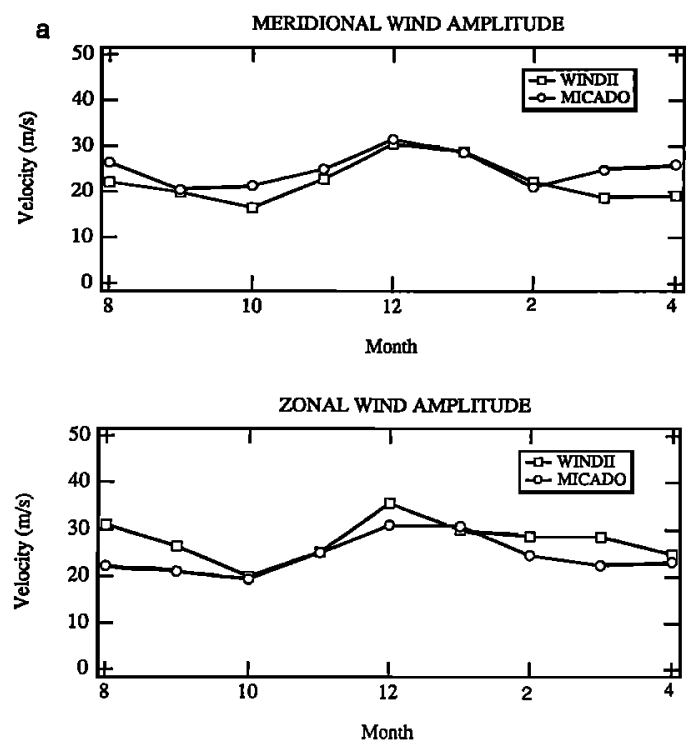
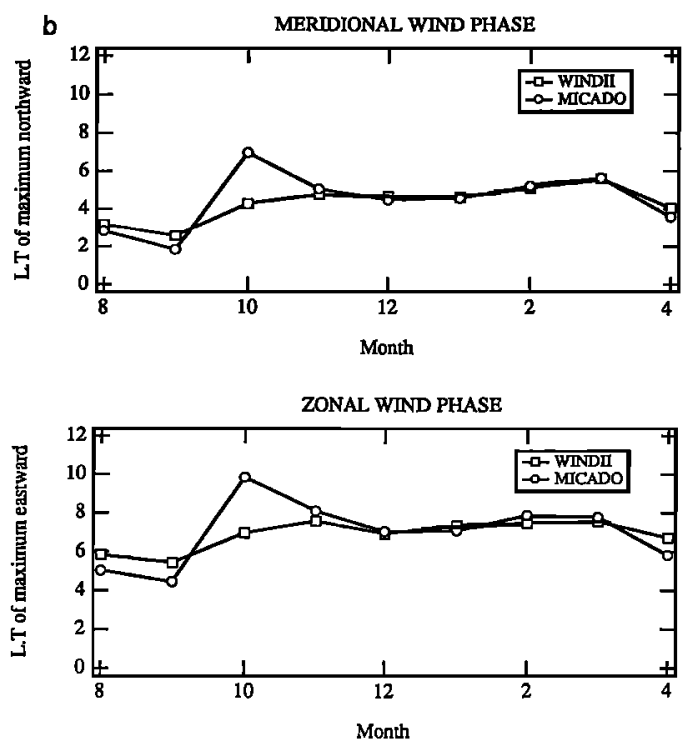

Figure 11. Comparison between the seasonal variation of the semidiurnal wind regime as derived from zonal average of WINDII data and MICADO observations at OHP. (a) Meridional and zonal amplitude of the semidiurnal tide, (b) meridional and zonal phase of the semidiurnal tide.

\subsection{Comparison With the OHP Semidiurnal Model}

At OHP, MICADO has been typically observing with a minimum of one complete night per month. For each month, these data were added to the measurements taken for the correlative periods. The resulting data set was analyzed by Fauliot et al. [1994] who provided the seasonal variation of the amplitude and phase of the semidiurnal tide of the two-wind components from August to April.

For each month, the WINDII observations made in the correlation area do not cover enough local time to allow an analysis of the wind variation as a function of time in terms of mean, diurnal, and semidiurnal circulation. Consequently, we applied a zonal average over the latitude range $\left[40^{\circ} \mathrm{N}-48^{\circ} \mathrm{N}\right]$ and used 2 months of data rather than 36 days as required to scan 24 hours of local time. Then, most of the local time range is covered except around twilight passes. These data are used to deduce the monthly amplitude and phase of the semidiurnal tide and to compare with those deduced from MICADO observations at OHP. Results are displayed in Figure 11. They are in quite good agreement, particularly during winter months while discrepancies of about $10 \mathrm{~m} \mathrm{~s}^{-1}$ in amplitude and more than 2 hours in phase arise at equinoxes. However, we are aware that some rapidly changing phenomenon may be damped due to the use of zonally averaged data and of a local time variation based on the 2-month averaging period of WINDII measurements. Furthermore, tidal characteristics may exhibit longitudinal variation, especially at the time of transitions of the wind flow [Lysenko et al., 1994]. This certainly leads to the masking, from WINDII data, of the strong phase transition in fall that is otherwise observed by MICADO.

\section{Conclusions}

Correlative measurements were carried out between WINDII and MICADO placed at OHP. Three different ways have been considered to compare data from orbit and from ground: direct correlations, correlations within \pm 5 days, and correlations within a month for comparing WINDII data with mean monthly MICADO models. We have used data for the two instrument fields of view generated with the version V4.23 of the scientific production software providing the zonal and meridional components of the wind. Among all possible direct correlations with OHP, only $22 \%$ were achieved. The few defective correlations are mainly explained by abnormal WINDII profiles of intensity, temperature or wind. The following results have been derived for improving the characterization of the night-time WINDII observations.

No trend as a function of time seems detectable with the data used in this study. For the viewing conditions as met around OHP, it appears that WINDII overestimates the meridional and zonal wind components by $10 \mathrm{~m} \mathrm{~s}^{-1}$. The three methods of comparison provide consistent results.

This wind difference has been related to the two instrument fields of view. It corresponds to an overestimate of $9 \mathrm{~m} \mathrm{~s}^{-1}$ on both fields. This result is due to the method of characterization of the zero wind phase of the instrument. A wind offset per field of view generates a variable offset along the orbit track for the resulting meridional and zonal wind components due to the geometry of the combination of line-of-sight winds. With an overestimate of $9 \mathrm{~m} \mathrm{~s}^{-1}$ per field the two horizontal wind components can be affected by a variable offset of $\pm 12 \mathrm{~m} \mathrm{~s}^{-1}$.

The amplitude and phase of the semidiurnal tide, as observed by MICADO from ground and WINDII in orbit, are similar. A discrepancy found around equinoxes has been explained.

Acknowledgments. The WINDII project is sponsored by the Canadian Space Agency and the Centre National d'Etudes Spatiales. Additional support for science analysis is provided by the Natural Sciences and Engineering Research Council of Canada and the Centre National de la Recherche Scientifique. The MICADO experiment has been developed at Service d'Aéronomie (SA), the Observatoire de Haute-Provence (OHP), the Centre d'Etudes et de Recherches en Geodynamique et Astrométrie (CERGA), and the Centre d'Etudes Spatiales du Rayonnement (CESR). The data processing has been led by G. AZRIA (SA). The MICADO investigation has been supported by the Institut National des Sciences de l'Univers, the Centre National 
d'Etudes Spatiales, and the Centre National de la Recherche Scientifique (GRECO Plasma E and PAMOY). We thank J. L. Chevassut and $\mathrm{M}$. Fehrenbach for operating the MICADO instrument according to the correlative measurements program and the Observatoire de Haute-Provence for supporting these observations.

\section{References}

Bouchareine, P., and P. Connes, Interferometer with compensated field for Fourier transform spectroscopy, J. Phys., 24, 134-138, 1963.

Fauliot, V., G. Thuillier, and M. Hersé, Observations of the F-region horizontal and vertical winds in the auroral zone, Ann. Geophys., 11, 17-28, 1993.

Fauliot, V., G. Thuillier, and M. Hersé, Observations of the E-region horizontal winds in the auroral zone and at mid-latitudes by groundbased interferometry, Ann. Geophys., 13, 1172-1186, 1995.

Forbes, J. M., and F. Vial, Monthly simulations of the solar semidiurnal tide in the mesosphere and lower thermosphere, J. Atmos. Terr. Phys., 51, 649-662, 1989.

Lilensten, J., G. Thuillier, C. Lathuillere, W. Kofman, V. Fauliot, and M. Hersé, EISCAT-MICADO coordinated measurements of meridional wind, Ann. Geophys., 10, 603-618, 1992.

Lysenko, I. A., Y. I. Portnyagin, A. N. Fakhrutdinova, R. A. Ishmuratov, A. H. Manson, and C. E. Meek, Wind regime at $80-110 \mathrm{~km}$ at mid-latitudes of the northern hemisphere, J. Atmos. Terr. Phys., $56,31-42,1994$.

Manson, A. H., C. E. Meek, H. Teitelbaum, F. Vial, R. Schminder, D. Kurschner, M. J. Smith, G. J. Fraser, and R. R. Clark, Climatologies of semi-diurnal and diurnal tides in the middle atmosphere $(70-110$ $\mathrm{km}$ ) at middle latitudes $\left(40-55^{\circ}\right), J$. Atmos. Terr. Phys., 51, 579-593, 1989.

Massebeuf, M., R. Bernard, J. L. Fellous, and M. Glass, Simultaneous meteor radar observations at Monpazier $\left(44^{\circ} \mathrm{N}\right)$ and Punta Boriquen $\left(18^{\circ} \mathrm{N}\right)$, II, Mean zonal wind and long period waves, J. Atmos. Terr. Phys., 43, 535-542, 1981.
McLandress, C., Y. Rochon, G. G. Shepherd, B. H. Solheim, G. Thuillier, and F. Vial, The meridional wind component of the thermospheric tide observed by WINDII on UARS, Geophys. Res. Lett., 21(22), 2417, 1994.

Meek, C. E., and A. H. Manson, Vertical motions in the Upper Middle Atmosphere from Saskatoon $\left(52^{\circ} \mathrm{N}, 107^{\circ} \mathrm{W}\right)$ M. F. Radar, J. Atmos. Sci., 46, 849-858, 1989.

Shepherd, G. G., et al., The wind imaging interferometer on the Upper Atmosphere Research Satellite, J. Geophys. Res., 98, 10725-10750, 1993.

Sipler, D. P., M. A. Biondi, and M. E. Zipf, Vertical winds in the midlatitude thermosphere from Fabry-Perot Interferometer measurements, J. Atmos. Terr. Phys., 57, 621-629, 1995.

Thuillier, G., and M. Hersé, Thermally stable field compensated Michelson interferometer for measurement of temperature and wind of the planetary atmospheres, Appl. Opt., 30, 1210-1220, 1991.

Thuillier, G., and G. G. Shepherd, A fully compensated Michelson interferometer of fixed path difference, Appl. Opt., 24, 1599-1603, 1985.

Thuillier, G., C. Lathuillere, M. Hersé, C. Senior, W. Kofman, M. L. Duboin, D. Alcayde, F. Barlier, and J. Fontanari, Co-ordinated EISCAT-MICADO interferometer measurements of neutral winds and temperatures in E- and F-regions, J. Atmos. Terr. Phys., 52, 625-636, 1990.

L. Bourg, V. Fauliot, M. Hersé, and G. Thuillier (corresponding author), Service d'Aéronomie du CNRS BP No. 3, 91371 Verrièresle-Buisson Cedex, France.

G. G. Shepherd, Centre for Research in Earth and Space Science, York University, Toronto, Ontario, Canada.

(Received November 9, 1994; revised October 21, 1995; accepted November 10, 1995.) 